AperTO - Archivio Istituzionale Open Access dell'Università di Torino

\title{
Effects of Bit Chewing on Right Upper Quadrant Intestinal Sound Frequency in Adult Horses
}

\section{This is the author's manuscript}

Original Citation:

\section{Availability:}

This version is available http://hdl.handle.net/2318/157248

since 2016-10-04T09:05:23Z

Published version:

DOI:10.1016/j.jevs.2013.11.006

Terms of use:

Open Access

Anyone can freely access the full text of works made available as "Open Access". Works made available under a Creative Commons license can be used according to the terms and conditions of said license. Use of all other works requires consent of the right holder (author or publisher) if not exempted from copyright protection by the applicable law. 


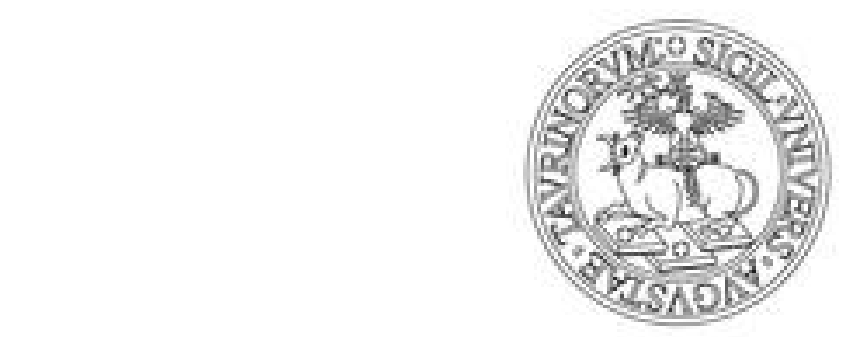

\section{UNIVERSITÀ DEGLI STUDI DI TORINO}

This Accepted Author Manuscript (AAM) is copyrighted and published by Elsevier. It is posted here by agreement between Elsevier and the University of Turin. Changes resulting from the publishing process - such as editing, corrections, structural formatting, and other quality control mechanisms - may not be reflected in this version of the text. The definitive version of the text was subsequently published in JOURNAL OF EQUINE VETERINARY SCIENCE, 34, 2014, 10.1016/j.jevs.2013.11.006.

You may download, copy and otherwise use the AAM for non-commercial purposes provided that your license is limited by the following restrictions:

(1) You may use this AAM for non-commercial purposes only under the terms of the CC-BY-NC-ND license.

(2) The integrity of the work and identification of the author, copyright owner, and publisher must be preserved in any copy.

(3) You must attribute this AAM in the following format: Creative Commons BY-NC-ND license (http://creativecommons.org/licenses/by-nc-nd/4.0/deed.en), 10.1016/j.jevs.2013.11.006

The definitive version is available at: http://linkinghub.elsevier.com/retrieve/pii/S0737080613008460 


\section{The effects of bit chewing on right upper quadrant intestinal sounds frequency in adult horses}

\section{Introduction}

Postoperative ileus (POI) is a recognized complication of abdominal surgery $[1,2]$. The reported incidence of ileus in horses ranges from $14 \%$ to as high as $47 \%[1,3,4]$ and higher if only small intestinal diseases are considered. Postoperative ileus carries also a high mortality rate, which can be up to the $86 \%$ [1-5].

Although other causes have been proposed [1], POI is supposedly caused by surgical manipulation and inflammation [6-8]. Many therapies have been proposed to prevent and treat POI in horses [9] but to date none is considered fully effective.

For this reason probably POI management require a multi-disciplinary approach that comprise drugs, nasogastric intubation, fluid therapy and all other measures that could possibly help in its prevention and treatment.

In horses, like humans postoperative ileus may involve the entire gastrointestinal tract [10-13] and prevention and treatment are based on same principles. Management strategies for POI can be divided into prevention and supportive care. In human medicine the choice of anesthesia, the surgical technique, and the means of providing pain relief, such as thoracic epidural analgesia [14], can play an important role in prevention. For supportive care, considerable research has looked into avoiding the use of routine NG intubation, early ambulation, early oral feeding, and prokinetic agents [14]. These strategies have been incorporated into fast track protocols designed to shorten POI and hasten discharge [15]. 
Aside of pharmacological treatment that doesn't differ substantially between horses and humans, other factors have been considered in the prevention of POI in humans [11]. Among these early feeding and gum chewing are the most recent yet promising. Although there is no confirmed evidence of the effectiveness of gum chewing, it seems to have some success in reducing time from surgery to first fecal passage and hospitalization time $[11,16,17]$

Early feeding can rarely be encouraged in equine patients suffering from POI and gastric reflux. Our hypothesys is that gum chewing or, better said, some sort of sham feeding that cause horses to chew without loading the gastrointestinal tract with food could be beneficial in improving gastrointestinal motility thus preventing or treating POI.

The aim of the present study is to produce a method to consistently induce horses at chewing without ingesting food and to evaluate its effects on gut sounds in healthy horses.

\section{Materials and methods}

The study received the approval of the Ethical and Animal Welfare Committee of the Department of Veterinary Sciences of the University of Turin and an information sheet was signed by owners. Ten healthy horses ( 6 standardbred, 4 warmblood) of both genders (2 intact males, 4 geldings, 4 mares) with ages ranging from 3 to 6 years and mean weight $500 \pm 34 \mathrm{~kg}$ were included in the study. All subjects underwent a clinical examination to exclude intestinal or other pathologies. History of normal feeding behavior was obtained for each horse. The study has been conducted in an environment familiar to the animal to avoid external confounding factors. To avoid influence of 
feeding times all horses were subjected to the experiments after a fasting time of at least 4 hours.

Each subject underwent three sessions one week apart with different order to reduce individual variability or variability due to fasting time.

Horses were cross-tied in the stable and an area approx $10 \mathrm{~cm}$ diameter was clipped on the right upper flank between the tuber coxae and the last rib, dorsal to the crus of the oblique external abdominal muscle. As previously described [18], a digital phonendoscope connected to a laptop and held by an operator was positioned in this area and the site marked with a permanent marker to ensure correct positioning at each examination.

A first registration was started and lasted for five consecutive minutes. Then a snaffle bit with toggles (Fig.1) was applied to the horse and a second registration started soon after and lasting 18 minutes.

Because in a preliminary study we found that a consistent increase in gut sounds started from approximately 3 minutes after bit application, the first 3 minutes of each registration were discarded. Remaining 5- minutes recording sessions were randomly numerated and assessed blindly by two operators that counted the total number of borborygmi for each session.

Borborygmi were classified in two categories, ones lasting less and ones lasting more than 3 seconds.

For each period of 5 minutes in each session the number of borborygmi per minute was then obtained and compared using commercially available statistical software (GraphPad InStat $\left.{ }^{\circledR}\right)$. 
A rANOVA Friedman test with Dunn post-test was performed to compare number of borborygmi per minutes between the 5 minute pre-chewing with 5,10 and 15 -minutes post chewing sessions.

\section{Results}

All horses tolerated the procedure. Application of a bit produced consistent mastication and swallowing in all horses that started soon after and lasted for a period of approximately 20 minutes. An increase in frequency of short sounds was evident from $3 \pm$ 0.7 minutes after starting chewing.

We noted a significantly different increase in short $(<3 \mathrm{sec})$ gut sounds in the first $5 \mathrm{~min}$ of registration (Table 1). After this period the frequency leveled but maintained values significantly different from the period pre-chewing.

Longer sounds $(>3 \mathrm{sec})$ didn't differed significantly in frequency between periods.

\section{Discussion}

In our study positioning of a bit produced consistent chewing for approximately 20 minutes. Chewing produced salivation and swallowing and increased frequency of borborygmi in the upper right quadrant starting from approximately 3 minutes after application. This finding could make bit chewing in horses similar to gum chewing in humans.

Bowel motility is regulated by intrinsic and extrinsic nervous modulation as well as by humoral substances. In humans, sham feeding as been postulated to increase vagal tone and the production of gastrointestinal hormones favoring and increase in intestinal motility [19]. 
In humans chewing gum is considered as a sham feeding which stimulates gut motility. It resulted in a shortening of time between surgery and defecation [16].

Although the exact causes of postoperative ileus are not fully understood, it has been postulated that an imbalance of sympathetic and parasympathetic inputs to the GI tract results in a reduction in propulsive motility, contributing to or causing signs of ileus [6$8,20]$.

In horses has been demonstrated that feeding cause an increase in gut sounds [18]. Although maybe a component of the increase motility is given by food composition, mastication, salivation and swallowing may play a fundamental role in horses too. In our study mastication of a bit consistently caused an increase in gut sounds detected with electronic auscultation on the right upper quadrant, as food administration did in a recent study [18].

Right upper quadrant borborygmi of short duration have been correlated with cecal segmental contractions causing mixing of ingesta [20] while propulsive motility associated with ileocecal valve emptying was associated with long, rumbling borborygmi. We classified borborygmi in ones lasting less or lasting more than 3 seconds. In our study we found only a statistically significant difference in frequency of borborygmi lasting less than 3 seconds. We cannot declare these increased borborygmi corresponds to an increased propulsive motility, lacking a clear correlation between the two. We found very few long, high intensity sounds in our study, opposite as others did [20]. This could be related to the absence of ingesta and to the absence of large amounts of gastric and enteric fluids, avoiding the necessity of long, propulsive waves. 
Auscultation is clinically a fundamental tool to evaluate gut motility although there is a poor interobserver correlation [18]. Computer aided auscultation allow more objective analysis of gut sounds although some interobserver disagreement can still occur [18]. In our experiment, to reduce individual and interobserver variation we classified borborygmi into two categories, those lasting less and those lasting more than 3 seconds. Still we cannot give exact evaluation of the intestinal activity when comparing electronic auscultation to other techniques like ultrasonography or intestinography.

For this reason we cannot state we assisted at an increased intestinal motility but nevertheless we assisted to increased gut sounds that maybe to correlated to increased motility. This is the first report, to our knowledge, about the effects of mastication, salivation and swallowing on intestinal activity in horses.

\section{Conclusions}

Our findings could set the basis for future research, eventually using intestinography, on the effects of sham feeding on the intestinal motility in healthy and diseased horses. As stated for humans [17] may be that chewing without food ingestion can not fully prevent POI, but because it is easily achieved and does not seems to cause any harm, it could be an accepted treatment. Perhaps placement of the bit two-three times per day in the postoperative period of a horse at risk of POI could result beneficial in the prevention and treatment of motiltity disorders. Furthermore in horses bit chewing is often part of their domestic life and is normally well tolerated.

In conclusion bit chewing can be easily obtained in horses at rest and further evaluation as an adjunctive element in the management of POI is warranted. 


\section{References}

1. Freeman DE et al.: Short-and long-term survival and prevalence of postoperative ileus after small intestinal surgery in the horse. Equine Vet. J. Suppl. 2000; 32:42-51

1. Morton AJ, Blinkslager AT: Surgical and postoperative factors influencing shortterm survival of horses following small intestinal resection: 92 cases (1994-2001). Equine Vet. J. 2002; 34: $450-454$

2. Blikslager AT et al.: Evaluation of factor associated with postoperative ileus in horses: 31 cases (1990-1992). J.Am. vet. Med. Ass. 1994; 205:1748-1752

3. Hunt JM, Edward GB and Clarke KW: Incidence, diagnosis, and treatment of postoperative complications in colic cases. Equine Vet. J. 1986; 18:264-270

4. Roussel AJ et al.: Risk factors associated with development of postoperative ileus in horses. J. Am. Vet. Med. Assoc. 2001; 219:72-78

5. Hopster-Iversen $\mathrm{C}$ et al. Influence of mechanical manipulations on the local inflammatory reaction in the equine colon. Equine. Vet. J.2011; 43 (Suppl 39): 1-7

6. Kalff JC at al. Intra-abdominal activation of local inflammatory response within the human muscularis external during laparatomy. Ann. Surg. 2003; 3:301-305

7. Schwarz NT et al. Selective jejunal manipulation causes postoperative panenteric inflammation and dysmotility. Gastroenterol. 2004; 126: 159-169

8. Koenig J, Cote N. Equine gastrointestinal motility- ileus and pharmacological modification. Can Vet J 2006; 47:551-559

9. Driscoll $\mathrm{N}$ et al. Large colon resection and anastomosis in horses: 52 cases (19962006). Equine Vet. J. 2008; 40:342-347 
10. Johnson MD, Walsh RM. Current therapies to shorten postoperative ileus. Clev Clin J Med 2009; 76(11): 641-649

11. Mair TS and Smith LJ. Survival and complication rates in 300 horses undergoing surgical treatment of colic. Part 1: short term survival following a single laparotomy. Equine Vet. J. 2005; 37(4): 296-302

12. Mair TS and Smith LJ. Survival and complication rates in 300 horses undergoing surgical treatment of colic. Part 2: short term complications. Equine Vet. J. 2005; 37(4): 303-309

13. Basse L et al. Gastrointestinal transit after laparoscopic vs open colonic resection. Surg Endosc 2003; 17: 1919-1922

14. Lubawski J and Saclarides T, Postoperative ileus: strategies for reduction. Therapeutics and Clinical Risk 2008; 4(5): 913-917

15. Meyer JP, Fawcett D. the use of chewing gum for preventing post operative ileus. BJ Intern 2007; 101: 1-3

16. Noble EJ, Harris R, Hosie KB, Thomas S, Lewis SJ. Gum chewing reduces postoperative ileus? A systematic review and meta-analysis. Int J Surg 2009; 7: 100-105 17. Naylor JM, Poirier KL, Hamilton DL, Dowling PM. The effects of feeding and fasting on gastrointestinal sounds in adult horses. J Vet Intern Med 2006; 20:1408-1413 18. Schuster $\mathrm{R}$ et al. Gum chewing reduces ileus after elective open sigmoid colectomy. Arch Surg 2006; 141: 174-176

19. Klohnen A. New perspectives in postoperative complications after abdominal surgery. Vet Clin North Am Equine Pract 2009; 25: 341-350 